\title{
Assessing the feasibility of cogeneration retrofit and district heating/cooling networks in small Italian islands
}

\author{
M. Beccali ${ }^{1}$, G. Ciulla ${ }^{1}$, B. Di Pietra ${ }^{2}$, A. Galatioto ${ }^{1}$, G. Leone ${ }^{1}$, A. Piacentino ${ }^{1, *}$ \\ *Corresponding author. Email: piacentino@dream.unipa.it \\ ${ }^{1}$ Dpt. of Energy, Information Engineering and Mathematical Models, \\ University of Palermo, Viale delle Scienze, Building no. 9, 90128, Italy; \\ ${ }^{2}$ ENEA, Unità Tecnica Efficienza Energetica, Via Anguillarese 301, 00123, Rome, Italy \\ Email addresses: ciullaina@dream.unipa.it; biagio.dipietra@enea.it; \\ giuliana.leone@dream.unipa.it; alessandra.galatioto@dream.unipa.it;
}

\begin{abstract}
Sustainability of energy supply strategies in small islands has been emerging as a severe issue, due to the large margins for improvement and rationalization of the most frequently adopted solutions. In most of the European islands, large amounts of heat are wasted by the operation of engine-based power plants; conversely, heat is produced by boilers (supplied by liquid fuels) or by electric equipment for a number of different uses, like domestic hot water production or space heating in winter. In this paper a techno-economic analysis is proposed to assess the feasibility of CHP-retrofit of the existing power plants and the possible utilization of the recovered heat to supply, via a district heating and/or cooling network, the energy requests of civil energy users (both in the tertiary and in the residential sector). The analysis is accurately performed for six islands located in Italy and characterised by different context conditions from a demographic, geographic and climatic viewpoint, so as to get a comprehensive understanding of the factors that favour/obstruct the economic feasibility of the examined technical solution. As expected, due to the low "linear heat density" usually observed in small islands and to the complex orographic profiles, the investment usually resulted "far from being attractive"; only in the case where public incentive or support mechanism is adopted, the possible integration of the existing power plants with heat recovery devices and a district heating network resulted in moderately attractive, especially in the largest examined islands due to their highest heat loads.
\end{abstract}

\section{KEYWORDS}

Cogeneration, trigeneration, residential/tertiary energy uses, load estimation, district heating/cooling, small islands, energy analysis, economic viability.

\section{INTRODUCTION}

Sustainable energy supply in remote areas like small islands represents an emerging research topic [1], since in many sites obsolete technologies and scarcely efficient energy uses may be encountered. In this regard, recent studies have suggested the use of integrated approaches to sustainability, aimed at addressing both the need for efficient energy supply and the problem of fresh water scarcity often experienced in such remote communities [2]. Fresh water production is prevalently achieved by Reverse Osmosis plants that consume significant amounts of electricity eventually produced by Renewable Energy Sources (RES) [3]. 
However, the contribution of RES to the total energy supply in small islands is often limited by grid stability concerns. In fact, though a large number of renewable sources is in general available [4], being that most of small islands are not or are only partially connected to continental electrical networks, appropriate management of energy supplies is required to reach a perfect balance between production and demand and sufficient electric grid safety standards. In a recent interesting paper a detailed survey was conducted for the French islands [5], pointing out that RES potential is often underused, accounting for a share between 5\% and $45 \%$ (with a $20 \%$ average) in terms of installed capacity and between $2 \%$ and $30 \%$ (with a $10 \%$ average) in terms of annual production. In particular, difficulties emerge with increasing penetration of intermittent energy sources (like solar PV and wind energy), characterised by high intermittence levels and stochastic character; when such sources are not available, in fact, other generation units have to compensate the lack of power and, consequently, sufficient reserve margins must be ensured (units supplied by fossil or predictable-renewable sources and already in part-load operation). Although advances in energy storage technologies are expected to weaken the problem in the medium-term, most of the energy systems currently installed on small islands have the following in common:

- A higher rate of exploitation of deterministic renewable energy sources (depending upon their local availability), such as hydropower [6] and biomass [7], compared to the aforementioned intermittent ones. In a very few cases, an appropriate mix of stochastic and flexible/predictable renewable energy sources has allowed to achieve very high RES penetration levels [8];

- The largest share of energy supply by diesel or heavy fuel oil, used in internal combustion engines. This result, that has been verified by an extensive survey at European Union (EU) level examining a significant number of small islands out of the 286 located within the EU territory [9], is due to a number of factors, such as: (i) the relative ease with which fuel can be purchased and supplied (compared to less attractive alternatives, such as natural gas to be transported either by pipelines or liquefied by tankers), (ii) the flexibility of engines (especially when designed by a modular approach) in meeting daily and seasonal variations in energy demand.

In spite of the high share of installed power generation capacity by diesel oil-fuelled Internal Combustion Engines (ICEs) and of the highly strategic outcomes that could be achieved for small islands [10], the penetration of Combined Heat and Power (CHP) in small islands is very low. This is mainly due to the following factors:

1. The difficulties in exploiting the recovered heat to supply a useful heat demand. Residential and non-domestic energy users are often disseminated over large areas (eventually characterized by complex orography), with a very low demographic density, thus making the viability of district heating (DH) or cooling (DC) networks hard to achieve;

2. The heat requests highly fluctuate on a seasonal basis. In many Mediterranean islands the heat loads for space heating are quite low, both because of the mild climate and the small share of permanent residents (compared to the annual peak of presences), especially in sites with a touristic vocation.

In a recent document assessing the CHP potential in Malta [11], it is clearly stated that feasibility of a small-medium scale district heating (and cooling) network is a preliminary condition to favour the penetration of cogeneration or trigeneration; in the same work two main barriers to the spread of district heating are identified: (i) the prevalent use of electric heating in standalone residential users, due to the absence of natural gas grids, (ii) the short space heating season due to the mild climate.

Despite district heating represents a well consolidated technological solution, with a high penetration especially in densely populated areas and cold climates, intense research activities have been conducted in the last few years as concerns possible improvements or identification 
of context-oriented design solutions. A very interesting work by Čulig-Tokić et al. [12] has presented a comparison between two different district heating systems serving two towns, Zagreb (Croatia) and Aalborg (Denmark); evident asymmetries were observed in terms of heat supply sources, total network length, supply temperatures and cost charging criteria for customers. In the search for the so-called 4th Generation District Heating concept [13], intended as systems which could operate as smart thermal grids and contribute to sustainability of energy supply, one of the main trends for the development of new installations consists in gradually lowering the water supply temperature, so as to reduce heat losses and increase the overall efficiency of the energy conversion chain. Ommen et al. [14] have analysed the positive impacts of low supply temperatures, in terms of increased efficiency of Combined Heat and Power systems eventually supplying the network (accounting for different power plant technologies), possible inclusion of district heating booster heat pumps and overall results from the primary energy saving and $\mathrm{CO}_{2}$ emission viewpoints. Recently, Østergaard and Lund [15] developed a technical scenario where the assumption of very low supply temperature was formulated to allow exploiting the large amounts of low temperature geothermal energy and thus converging toward the declared goal of making the Danish city Frederikshavn a $100 \%$ renewable energy city.

The present paper, conversely, is aimed at identifying solutions to increase the overall energy efficiency in small islands, with a particular focus on six islands in Italy. The ambitious goals declared in the above referenced works (like the $100 \%$ renewable energy scenario) become, for small islands, absolutely far from realistic. The state of art, as will be clarified in the following sections, reveals the presence of different very poor energy uses and an extremely low penetration of renewable sources. Then, the perspective of the research and the aim of the study is completely different than usual: the feasibility of DH/DC networks will be investigated only as a means to allow exploiting the enormous amounts of waste heat currently discarded, with no useful scope, by the power generation units (prevalently based on diesel generators) that supply electricity to these remote communities. While performing such pre-feasibility studies, the authors were aware that very unfavourable context conditions could represent strong barriers to the economic viability to be investigated; in fact, though any waste heat recovery virtually represents a "zero-cost" energy input to the network, the extremely low heat/cooling demand density and the difficult orography of the examined islands could contribute to make any DH/DC-based scenario unfeasible.

The problem of feasibility of district heating in low heat demand density areas is not new in literature. In the framework of the "Heat Roadmap Europe" projects, Persson et al. [16] investigated under what conditions the coexistence of heat supply/recovery options and possible heat consumers can offer a promising context for the feasibility of district heating. In another work the same authors systematically approached the problem of heat distribution cost assessment, providing tools and formulas to answer a very common problem in DH networks planning, i.e. the optimal extension of an urban network toward suburban-periphery areas where the share of built area gradually decreases [17]. It was pointed out that the distribution cost can be estimated as an inverse function of the "linear heat density" (ratio between the heat load and the length of the network branches needed to supply the load) and it is linearly dependent on the average tube pipe diameter, which ultimately influence also the cost of civil works for pipes installation. In the present work, these cited approaches are applied to the different islands, to identify reasonable network geometries and someway predict the feasibility of DH/DC.

The paper is structured as follows:

- in Section 2 the islands considered in this study are briefly presented, providing sufficient details about the distribution of energy users, the installed capacity and the estimated waste heat available; 
- in Section 3 the methodology followed to perform the prefeasibility study is discussed, point by point, in different subsections, specifically devoted to $(i)$ the estimation of energy loads, (ii) the estimation of distribution costs, aimed at identifying the most promising solutions as concerns the installation of "DH only", "DH\&DC" or "DC only" networks and the possible paths of the network, (iii) the identification of reasonable supply temperatures and the type of pipes to be installed, (iv) the detailed evaluation of investment costs and possible revenues from selling heat to private/public customers;

- in Section 4 a brief overview of the values achieved by synthetic economic performance indicators is given, attempting to provide some keen interpretations of the reasons leading to feasibility or unfeasibility of the examined "CHP + DH/DC" retrofit options.

The methodology is punctually examined, although some description could appear, only at a first sight, as a simple implementation of consolidated techniques. In fact, the atypical morphology of the served community (compared to the urban areas usually supplied by district heating in Europe) contributed to make the whole DH design and evaluation process a highly non-standardized approach, which required several ad hoc decisions to be taken and consequently represents an innovative contribution with evident methodological interest; it is worthwhile observing that no such detailed studies can be found, in literature, as concerns the design of cogeneration and district heating network in disadvantaged areas like small islands.

\section{THE EXAMINED CASE STUDY: SIX SMALL ISLANDS IN ITALY}

Due to their geographical position, many small islands laying into the Italian territory are today not connected to the national electric grid. In these islands, private companies supply almost the $100 \%$ of the consumed electricity by means of local power plants fired by fossil fuels. Present study belongs to a research project on the feasibility of CHP retrofit actions of these power generation units to be connected to new distribution networks for fulfilling thermal end-uses in the neighbours. Currently, most of the power generation units are operated in pure powerproduction mode. Due to the very high production cost (related with the cost of fuel shipping and the moderately low efficiency of diesel engines, compared to large power plants), they receive a special subsidized feed-in tariff, named "UC4", for the produced electricity [18]. One of the analysed hypotheses is that an economic exploitation of a fraction of the waste heat currently discharged could reduce the cost of power supply in such remote communities.

The islands that have been analysed in this study differ each other for dimension, density of population and climatic conditions (as shown in Table 1). Lampedusa and Linosa are the most Southern and host one of the only two Municipalities in Italy laying in the Climatic Zone A (568 Heating Degree Days - HHD). On the other hand, Isola del Giglio is the most northern island of the sample and it is the only one laying in the Climatic Zone D (2084 HHD) where the winter heating demand is very relevant.

Table 1. Main data for the analysed islands (coordinates refer to the power plant site)

\begin{tabular}{|c|c|c|c|c|c|c|c|}
\hline Island & Latitude & Longitude & HDD & $\begin{array}{l}\text { Climate } \\
\text { Zone }\end{array}$ & Area & Inhabitants & $\begin{array}{c}\text { Population } \\
\text { density }\end{array}$ \\
\hline & $\mathrm{N}$ & E & {$\left[{ }^{\circ} \mathrm{C}\right]$} & {$[-]$} & [Km2] & {$[-]$} & {$\left[\mathrm{inh} . / \mathrm{Km}^{2}\right]$} \\
\hline Lampedusa & $35^{\circ} 30^{\prime} 14.9^{\prime \prime}$ & $12^{\circ} 37^{\prime} 13.2^{\prime \prime}$ & 568 & A & 20.2 & 6234 & 308.6 \\
\hline Linosa & $35^{\circ} 51^{\prime} 38^{\prime \prime}$ & $12^{\circ} 51^{\prime} 52^{\prime \prime}$ & 568 & A & 5.40 & 433 & 80.2 \\
\hline Ustica & $38^{\circ} 42^{\prime} 33.5^{\prime \prime}$ & $13^{\circ} 11^{\prime} 43.4^{\prime \prime}$ & 717 & B & 8.09 & 1309 & 161.8 \\
\hline Pantelleria & $36^{\circ} 49^{\prime} 40.4^{\prime \prime}$ & $11^{\circ} 56^{\prime} 04^{\prime \prime}$ & 717 & B & 83.0 & 7364 & 88.7 \\
\hline $\begin{array}{c}\text { Isola del } \\
\text { Giglio }\end{array}$ & $\begin{array}{l}42^{\circ} 21^{\prime} \\
47.47^{\prime \prime}\end{array}$ & $\begin{array}{l}10^{\circ} 52^{\prime} \\
50.04^{\prime \prime}\end{array}$ & 2084 & $\mathrm{D}$ & 23.8 & 1299 & 54.5 \\
\hline Favignana & $37^{\circ} 56^{\prime} 06.3^{\prime \prime}$ & $12^{\circ} 20^{\prime} 33.3^{\prime \prime}$ & 814 & B & 19.8 & 3975 & 200.7 \\
\hline
\end{tabular}


At the same time, the most populated island is Pantelleria although its demographic density is not actually the highest. The less populated island is Linosa. Lampedusa and Favignana reach the highest population density values, as shown in Tab. 1.

Figure 1 shows how the examined islands may be effectively grouped in clusters, in order to make possible a meaningful comparison of the outputs of the analyses. In particular, blue circles identify islands showing similar characteristics in terms of number of inhabitants, while red circles define sets of islands sharing the same climatic features in terms of HDD.

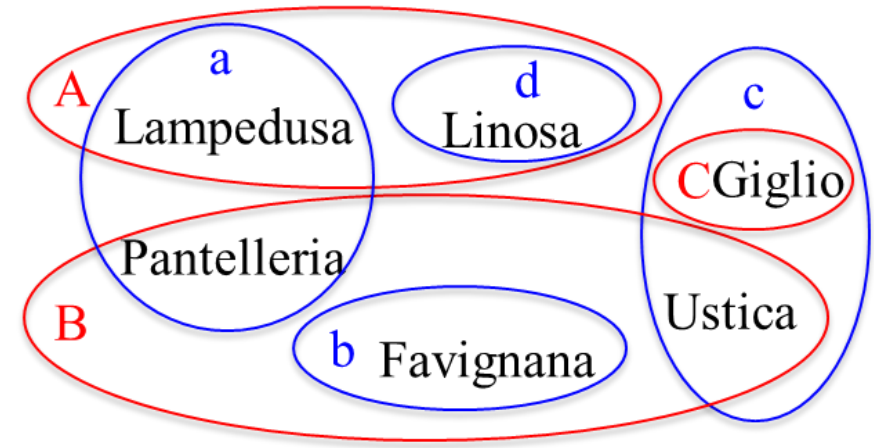

BLUE CIRCLE. Population criterion:

- group a: inhabitant > 6000;

- $\quad$ group b: $2000 \leq$ inhabitant < 6000;

- $\quad$ group c: $2000 \leq$ inhabitant $<1000$

- $\quad$ group $\mathrm{d}:<1000$

RED CIRCLE. Climatic criterion:

- Group A: HDD <600

- Group B: $601<$ HHD <900

- Group C: $901<$ HHD < 1400

Figure 1. Clusters of islands according to population and climatic criteria.

Other issues concerning the feasibility of district heat networks deal with the peculiar orography of islands.

Figure 2 highlights these issues by showing: the position of the power plant and the distance from the most densely populated areas; the possible "DH main" line sketched from the power plant to the urbanized area and, by the use of additional elements (blue and white circles with numbers, as depicted in the legend), the number and location of spot users belonging to the tertiary sector (e.g. hotels, schools). Potential "outliers", such as airports and prison, are also highlighted in Lampedusa, Pantelleria and Favignana districts. In general, it is worth noting that in each island we may distinguish between a relatively dense "urban area" (indicated in Figure 2) and large zones having a diffuse "low density" urbanization where the heat load density is evidently too low to justify any possible hot/warm/cold fluids distribution. For these reasons these areas are not considered in the rest of the analysis as concerns the evaluation of energy loads. Moreover, looking at islands orography, it is worth noting that Pantelleria and Isola del Giglio are characterized by the presence of hills in the area of main interest for the project. This represents an additional barrier and influence the definition of the "useful area" to be evaluated for the feasibility of a District Heating/Cooling network.

Finally, the pre-feasibility study cannot neglect the effects on the big asimetry during the year of load profiles strongly influenced by the touristic vocation of the islands. In particular, it has been noticed that almost 50\% of houses in the Pantelleria, Lampedusa and Favignana, 30\% in Isola del Giglio and $70 \%$ in Ustica are not generally occupied during winter [19] while touristic reports [20] confirm that the peak of touristic fluxes are everywhere registered during August. 

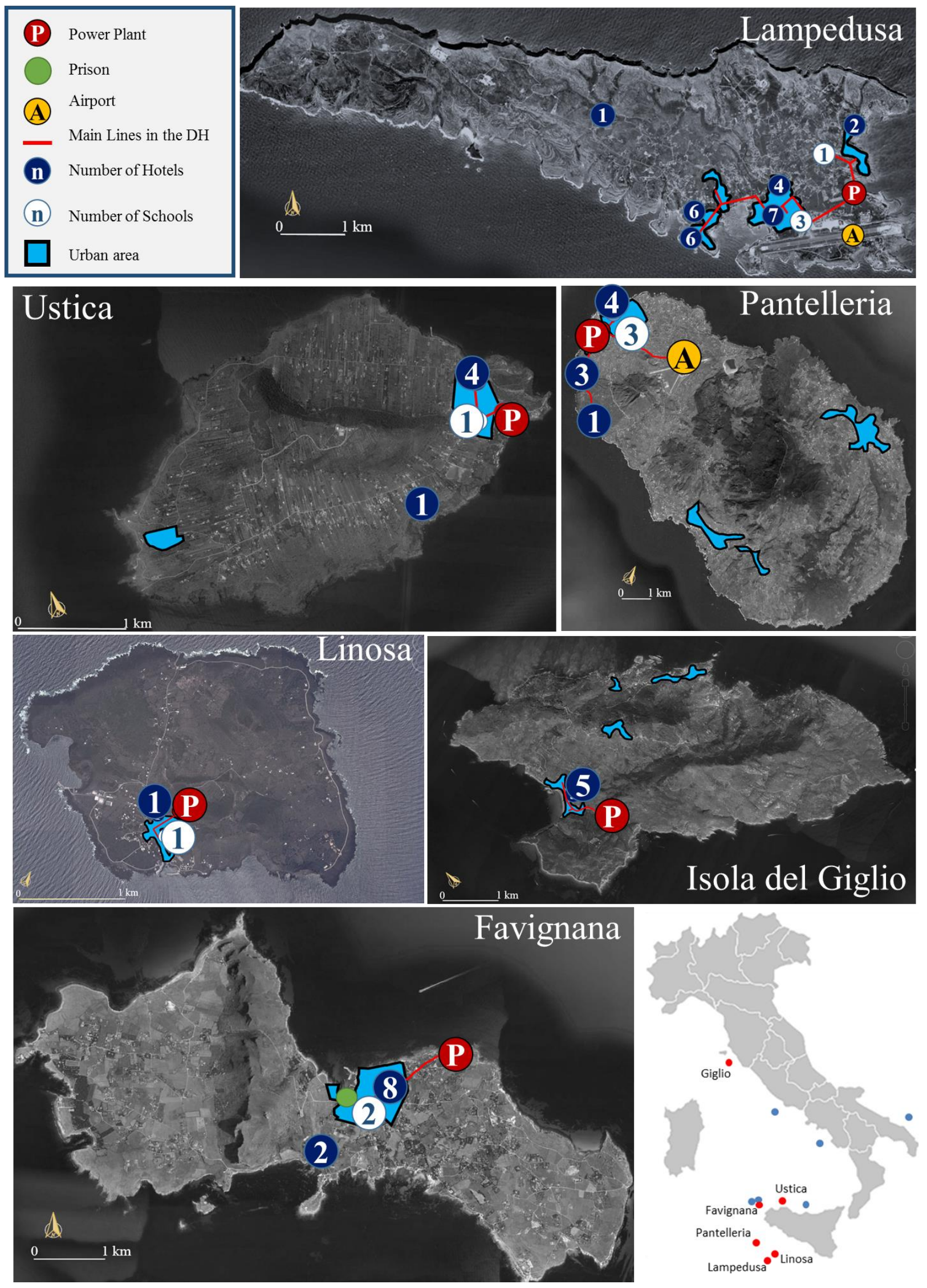

Figure 2. Graphic representation of topic figures in the analysed islands 


\section{Installed capacity}

In order to maintain an appropriate safety of supply, adequate levels of redundancy are needed in case of a failure for a producing unit; also, due to the need for a more flexible operation to follow the highly fluctuating loads, the installation of several smaller diesel engines is usually preferred to the installation of one or two large generators. In Table 2 details on the installed capacity, the waste heat production rate (values are calculated at a $75 \%$ maximum load, following the suggestions received by plant owners about the typical operating strategy adopted) and the number of individual units installed are given. As concerns the heat production rate, low temperature waste heat from the cooling jacket water circuits is distinguished by high-grade heat from exhaust gases.

Table 2. Technical data concerning the power generation systems

\begin{tabular}{lcccc}
\hline \multicolumn{1}{c}{ Island } & $\begin{array}{c}\text { Installed } \\
\text { capacity }\left[\mathrm{MW}_{\mathrm{e}}\right]\end{array}$ & $\begin{array}{c}\text { Low temp. waste } \\
\text { heat rate }\left[\mathrm{MW}_{\mathrm{t}}\right]\end{array}$ & $\begin{array}{c}\text { High temp. waste } \\
\text { heat rate }\left[\mathrm{MW}_{\mathrm{t}}\right]\end{array}$ & $\begin{array}{c}\text { Number of units installed to } \\
\text { fraction the overall capacity }\end{array}$ \\
\hline Lampedusa & 22.56 & 6.67 & 8.63 & 8 \\
Pantelleria & 25.03 & 7.40 & 9.65 & 8 \\
Favignana & 9.62 & 4.74 & 3.71 & 7 \\
Ustica & 5.87 & 2.88 & 2.25 & 5 \\
Giglio & 8.19 & 4.03 & 3.16 & 7 \\
Linosa & 2.61 & 1.29 & 1.01 & 6 \\
\hline
\end{tabular}

\section{METHODOLOGY}

\section{(i) The assessment of energy loads}

The methodology discussed in this section was applied to all the examined islands. All potential users in the territory were grouped in suitable clusters, whose limits were defined looking at the actual spatial distribution of buildings. The methodology requires determining, for each spatial cluster, an overall monthly energy demand as well as its shares for two main categories: (i) residential users (usually grouped in quite omogenous areas) and (ii) spot users of the tertiary sector. In order to provide a reliable assessment of aggregated energy loads, specific energy loads (referred to $\mathrm{m}^{2}$ of building area or to occupant) were preliminarily calculated. Thus an integration over the set of buildings located in each specific cluster was carried out. In particular, footprint area was used as reference unit for residential users. For this user category the final energy demand was calculated by means of dynamic building simulation software. The specific energy demand of spot users refers to literature values. H/C energy needs for schools and prison have been referred to their built volume while DHW energy needs for hotels depends on the number of beds being these values reported in many reports/standards usually used for rapid energy audits. Energy demand of "outliers" has been assessed from available energy audits.

Residential energy demand has been estimated using the EnergyPlus software [21] doing simulations for a set of reference buildings . Their geometrical and constructive characteristics have been defined from the information available in the ISTAT Census database 2011 and from the Report 2/2003 issued by the Thermo technic Italian Committee (Comitato Termotecnico Italiano - CTI) [22].

In particular, information about building age and construction typology has been extracted from the ISTAT database, available for each island, and have been arranged and crossed with 
typical wall layers data coming from the CTI report which classifies wall layers according to Italian geographic areas, building age and constructive framework (Figure 3). The following criteria have been applied: (i) the most spread construction typology in each island has been considered; (ii) the building-age classification by ISTAT has been grouped according to the CTI building-age classification; (iii) Tuscany sample in the CTI report has been considered representative for Isola del Giglio; (iv) South Italy sample in the CTI report has been considered representative for Sicilian Islands. It is worth noting that Census data are grouped by Municipality and for this reason, being Lampedusa and Linosa a unique legal entity, have been handled together as far as Favignana which encloses also the islands of Levanzo and Marettimo.

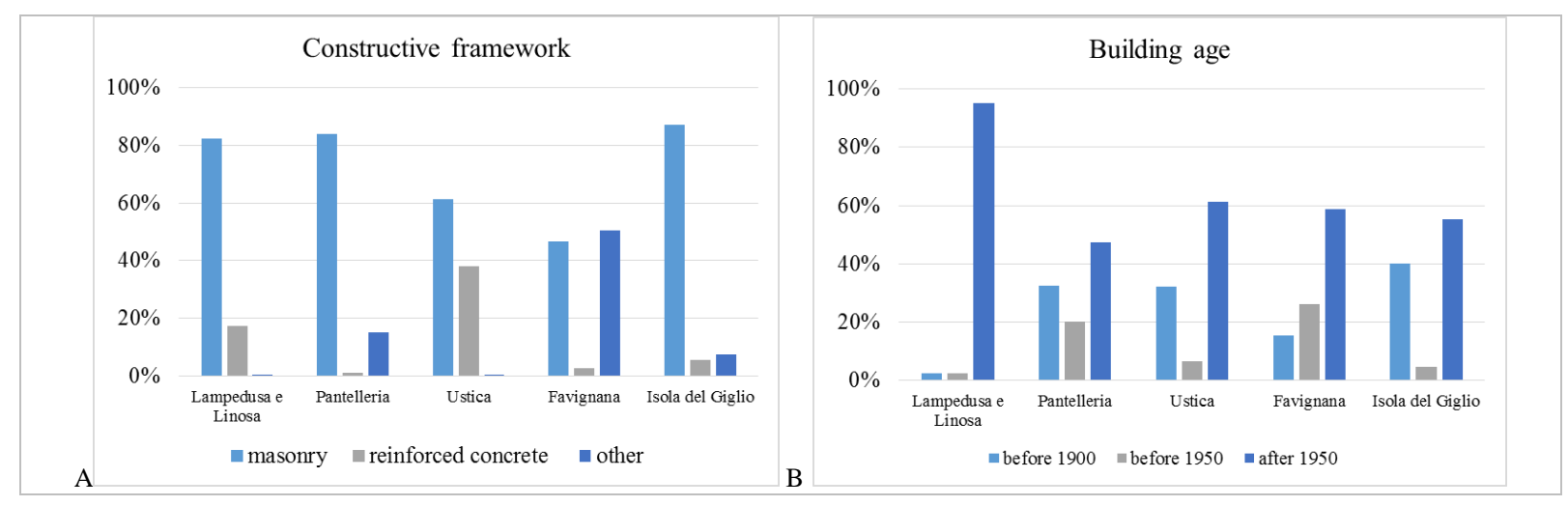

Figure 3. Building constructive frameworks (A) and ages (B)

As a result, two wall packages have been considered for each island, as shown in Figure 3. They are: plaster/tuff stone/plaster $\left(\mathrm{U}-\right.$ Value $\left.=1.15 \mathrm{Wm}^{-2} \mathrm{~K}^{-1}\right)$ and plaster/clay brick/plaster $\left(\mathrm{U}-\right.$ Value $\left.=0.57 \mathrm{Wm}^{-2} \mathrm{~K}^{-1}\right)$. Ground, ceiling and roof structures have been assumed to be made in reinforced-concrete in all cases $\left(\mathrm{U}_{\text {ground }}=0.83 \mathrm{Wm}^{-2} \mathrm{~K}^{-1} ; \mathrm{U}_{\text {roof }}=1.23 \mathrm{Wm}^{-2} \mathrm{~K}^{-1}, \mathrm{U}_{\text {ceiling }}=1.71\right.$ $\mathrm{Wm}^{-2} \mathrm{~K}^{-1}$ ), while single-glass and aluminum frame without thermal break are supposed to be the only window typology $\left(\mathrm{U}_{\mathrm{W}}=5.1 \mathrm{Wm}^{-2} \mathrm{~K}^{-1}\right)$. It is worth noting that only in Lampedusa/Linosa it was possible to define a unique model of buildings laying in the area of interest, being them mainly of the same age and built in masonry structure. For the other islands, different wall packages and building typologies have been considered.

Reference buildings geometry can be inferred by the ISTAT database. For each island, it was possible to identify the percentage of buildings with different number of floors and the average number of apartments per building as the ratio between the total number of apartments $(\mathrm{Na})$ and the total number of buildings $(\mathrm{Nb})$. Three different reference buildings have been defined according to the number of floors (A, B and C in Figure 4). It is worth to note that a certain correspondence between the highest percentage of buildings with a defined number of floors and the average number of apartment occurs. It is then reasonable to suppose that the reference building has one apartment per floor. Building simulations have been performed assuming, in each building, one thermal zone per floor. Furthermore, the reference buildings are supposed to be square-shaped and grouped in squared or aligned blocks (respectively scheme 1 and 2 in Figure 4). Indeed, each island shows a peculiar urban structure and block schemes according also to the prevailing orientation of buildings and their boundary conditions. It must be noted that the other geometrical features have been desumed by the Italian building rules (minimum ceiling height: $2.7 \mathrm{~m}$ and minimum window area/floor area ratio $\mathrm{A}_{\mathrm{w}}=\mathrm{S}_{\text {res }} / 8$ ). 


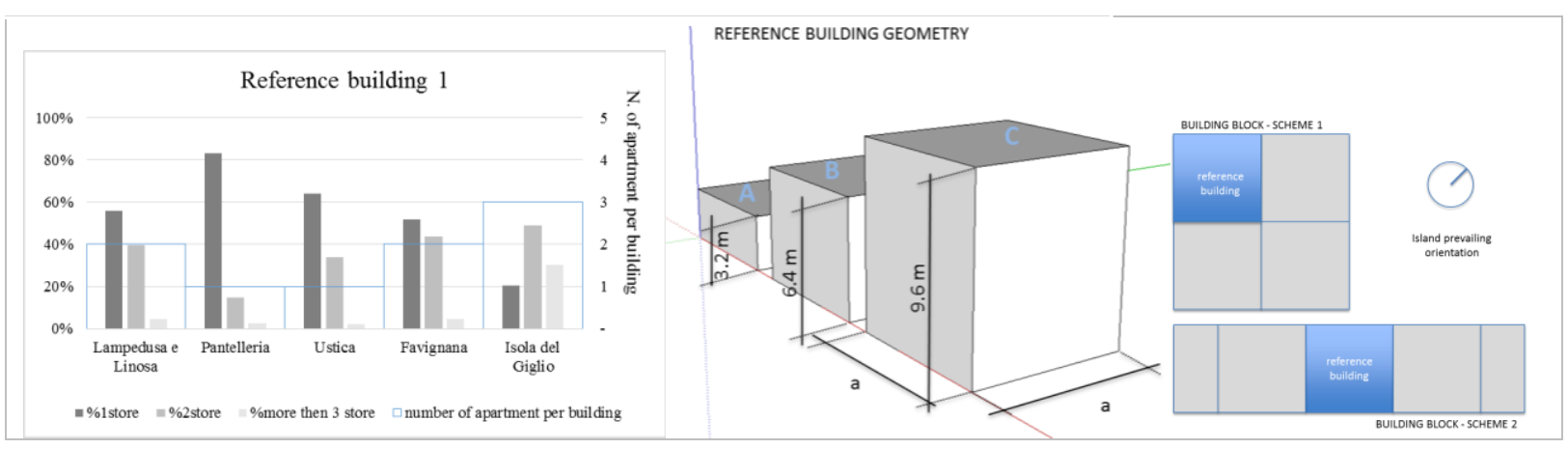

Figure 4. Reference buildings

The energy demand for space heating/cooling and for Domestic Hot Water purposes (respectively $\mathrm{Q}_{\mathrm{h} / \text { cres }}$ and $\mathrm{Q}_{\mathrm{DHW}}$.res) has been consequently calculated for the reference buildings as the sum of the energy demand of each apartment composing each building. Finally, the monthly and seasonal energy demand (measured in $\mathrm{kWh} / \mathrm{m}^{2}$ ) for residential buildings has been computed cluster-by-cluster according to Eq. (1) and (2):

$$
\begin{aligned}
& E_{h / c . \text { res }}=\frac{\sum Q_{h / c . r e s, n} \cdot P_{n}}{\sum P_{n}} \cdot N \cdot O c c \\
& E_{D H W . r e s}=\frac{\sum Q_{D H W, n} \cdot P_{n}}{\sum P_{n}} \cdot N \cdot O c c
\end{aligned}
$$

where: $E_{h / c . r e s}$ and $E_{D H W}$.res are the monthly energy demands of the cluster for respectively heating/cooling purposes and Domestic Hot Water supply; $\mathrm{P}_{\mathrm{n}}$ is a weighting factor which takes into account the percentage of building having $n$ floors (Figure 4); $\mathrm{N}$ is the number of building in the cluster and Occ is a parameter taking into account the touristic vocation of Italian Islands. In particular, the $\mathrm{N}$ value can be assessed as $\mathrm{A}_{\text {res }} / \mathrm{A}_{\text {tot }}$ (where $\mathrm{A}_{\text {tot }}$ is the total residential built area in the cluster), while Occ depends on the percentage of occupied apartment by inhabitant. Moreover, it has been supposed that houses in the island are fully occupied during summer months, while during the rest of the year only local people live in the island.

Being very high the touristic vocation of the islands, it must be highlighted that the hotels energy demand would have a big impact on the network feasibility. For this reason, they have been accurately censed and classified according to the number of beds and to the hotel rating system [23]. Present work refers to a study made by Beccali et al. [24] that focuses on energy demand of several categories of hotels in Sicily. Table 3 shows energy demand figures for heating and cooling for Isola del Giglio. These values have been evaluated introducing a weighting factor taking into account the different Heating Degree Days between Sicilian Island and Isola del Giglio. Finally, the DHW demand has been assessed according to national standard UNI/TS 11300-2:2014 [25].

Table 3. Space heating and cooling demands of hotels

\begin{tabular}{llcclllll}
\hline & & Group I (1-2 star) & Group II (3 star) & \multicolumn{3}{c}{$\begin{array}{c}\text { group III } \\
\text { (4-5 stars) }\end{array}$} \\
\hline & & & & & \multicolumn{4}{c}{ Tuscany } \\
\hline Heating & E $_{\text {h.hotel }}$ & 288 & 902 & 835 & 2143 & 1620 & 1805 & $\mathrm{kWh} / \mathrm{bed}$ \\
Cooling & $\mathrm{E}_{\text {c.hotel }}$ & 389 & 669 & 924 & 1937 & 778 & 3761 & $\mathrm{kWh} / \mathrm{bed}$ \\
\hline
\end{tabular}


It follows that monthly energy demand for hotels is evaluated according to the previous method by applying Eq. (3) and (4):

$$
\begin{aligned}
& E_{\text {TOT.h/c.hotel }}=E_{h / c . h o t e l} \cdot N_{\text {bed }} \cdot O c c_{\text {month }} \\
& E_{\text {TOT.DHW.hotel }}=E_{D H W . h o t e l} \cdot N_{\text {bed }} \cdot O c c_{\text {month }}
\end{aligned}
$$

where: Етот.h/chotel and Етот.DHW.hotel are the monthly energy demands of the cluster for respectively heating/cooling purposes and Domestic Hot Water supply, $\mathrm{N}_{\text {bed }}$ is the number of pax in the hotel and $\mathrm{O} c c$ is a parameter taking into account the touristic vocation of Italian Islands. According to the touristic flow, Figure 5 shows the Occ-values on a monthly basis. Main assumption for DHW curve is that all beds in the hotel are booked during summer and holydays periods. Meanwhile, the seasonal heating and cooling demand is considered proportional to the percentage of occupied beds with respect to heating and cooling period.

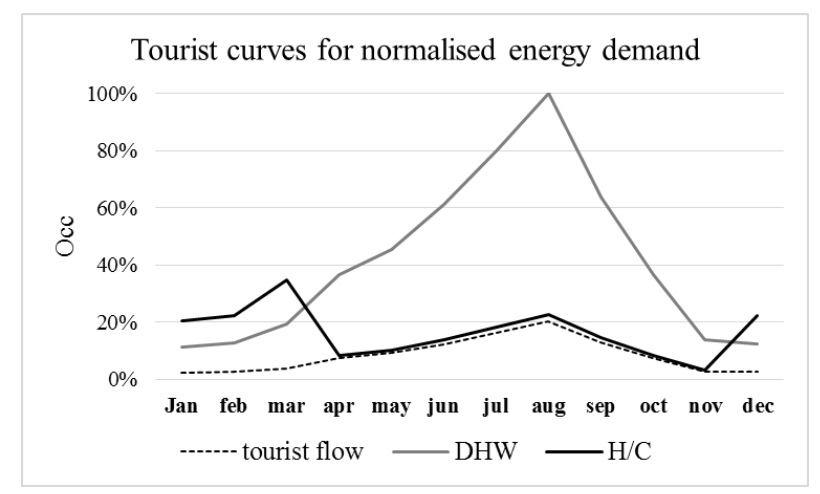

Figure 5. Occ and final demands monthly values

Finally, the assessment of energy demand for school has been obtained by extracting specific figures reported in case studies [26] grouped according to climatic zones. In particular, space heating demand has been calculated by assumingaverage values of specific figures. For the Penitentiary building in Favignana, average data for residential use for heating and cooling have been considered. Meanwhile, average unitary values per day for DHW production have been taken from Stoppato et al. [27].

Finally, dealing with the airports of Lampedusa and Pantelleria present work uses data extracted from two detailed energy audits which have been made in the framework of a National project (POIN) about Italian airports [28,29]. Specifically, the reports from the POIN project provide the actual energy consumption for air-conditioning and DHW production coming from in situ monitoring campaigns and software simulations. Overall results are shown in Figures 6 and 7. Absolute values are plotted island-by-island in Figure 6, where seasonal energy demand regardless end-users differentiation are shown with respect of the energy final use (Figure 6.A). The influence of residential and tertiary sector on the overall energy demand is shown in Figure 6.B distinguishing the three final-uses of energy.

A final note should be given on the level of time-resolution of the energy demand adopted in this paper. Due to the large difficulties that would be encountered in developing reliable daily load profiles, for the different time of users, energy demand have been calculated on a monthly basis. However, if large-scale heat storage is avoided, heat recovery from the engines may be exploited to supply (via a DH network) heat end-users only if production and demand are, at some extent, simultaneous. On the basis of interviews conducted with electric companies representatives and of a qualitative reconstruction of possible load profiles, it was agreed to deal with this problem by adopting a conservative reduction factor of 0.8 in order to 
pass from the "heat released from engine operation" to the "heat released and efficiently exploited to supply simultaneous heat loads".
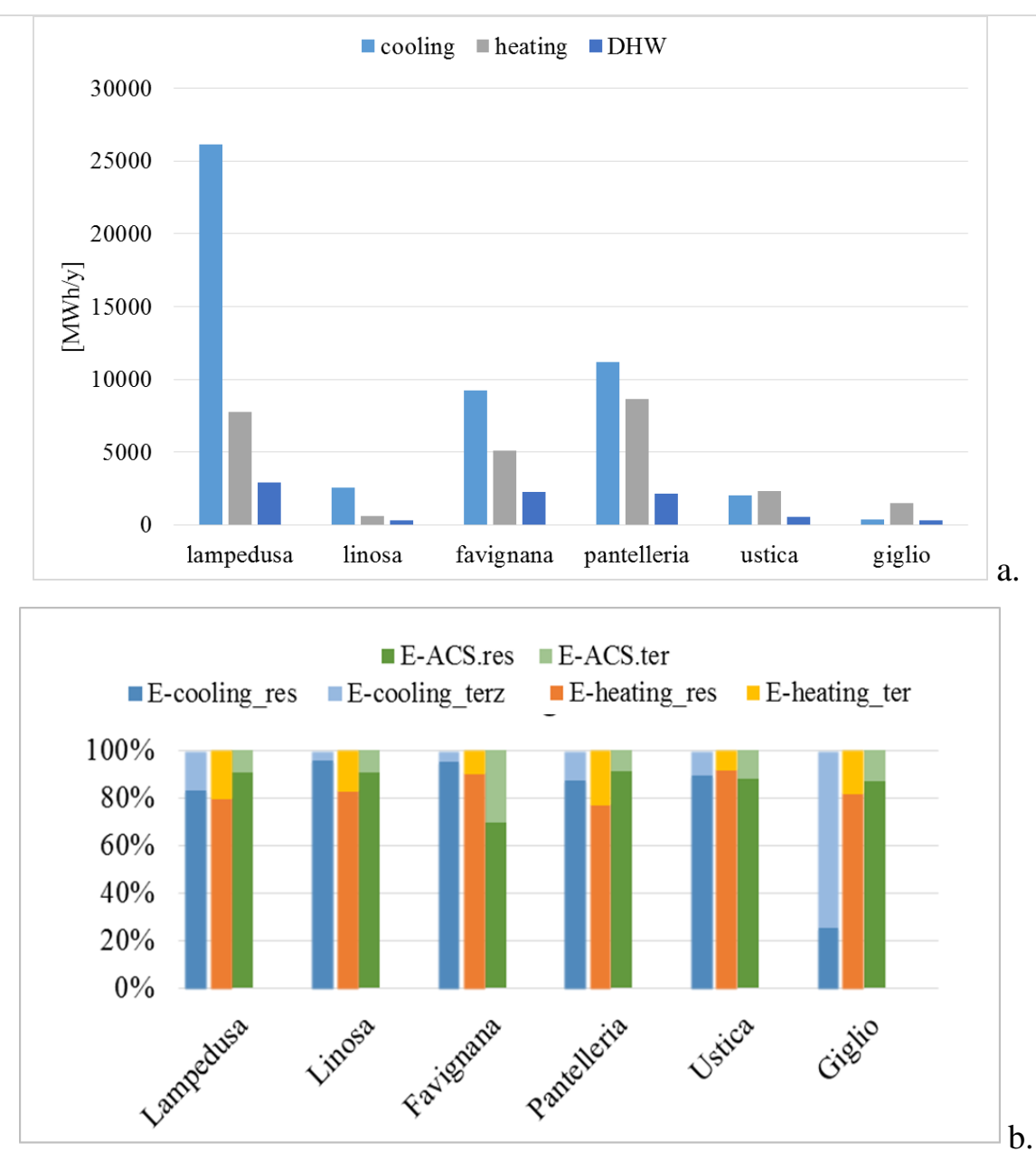

Figure 6. a. Energy demand, b. Monthly cooling trend.

Finally, Figure 7 shows monthly percentage of Heating $(\mathrm{H})$ and Cooling $(\mathrm{C})$ demands with respect to their peak values.

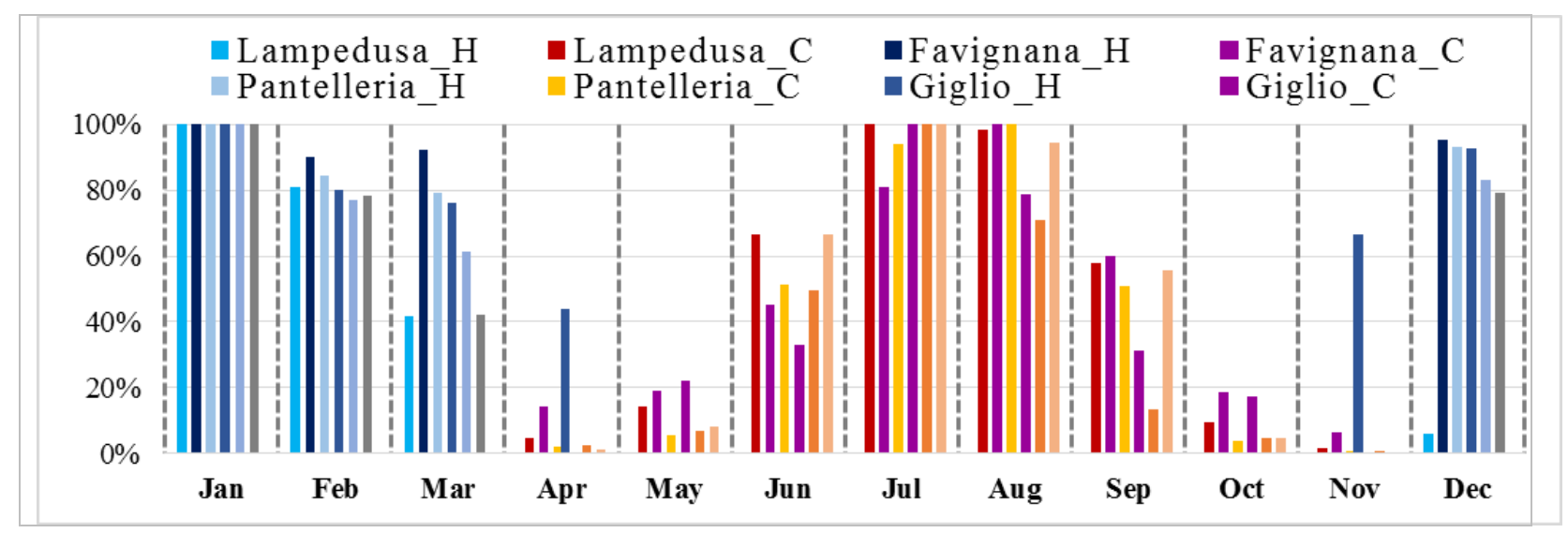

Figure 7. Monthly energy demand. 


\section{(ii) Estimation of distribution costs and identification of promising technologies and network geometries}

In the previous subsection it has been cleared how a reasonable estimation of thermal energy end uses could be obtained, classified by type of costumer (centralized/punctual, i.e. "large scale", and distributed/residential, i.e. "small scale" user) and energy request (domestic hot water, space heating and space cooling). In the present section the methodological approach followed to identify reasonable technological solutions to develop the district heating and/or cooling networks and their geometry will be discussed in details.

First of all, let us define a possible set of options/scenarios to be investigated, that are classified as follows:

a. Interconnection level: two alternative scenarios are considered, respectively based on assuming:

- a very high interconnection level of the networks, with the densely populated/built areas entirely covered by the hot/warm/cold fluids distribution network and the consequent possibility, for any centralized or residential customer, to be connected to the DH network upon request. This design option is illustrated, for an exemplificative island with two densely populated areas " 1 " and " 2 ", in Figure 8.a;

- a very low interconnection level of the network, based on assuming the installation of a limited number of pipes/branches, sufficient only to distribute the hot/warm/cold fluids toward the largest centralized/punctual customers. This option is illustrated in Figure 8.b;

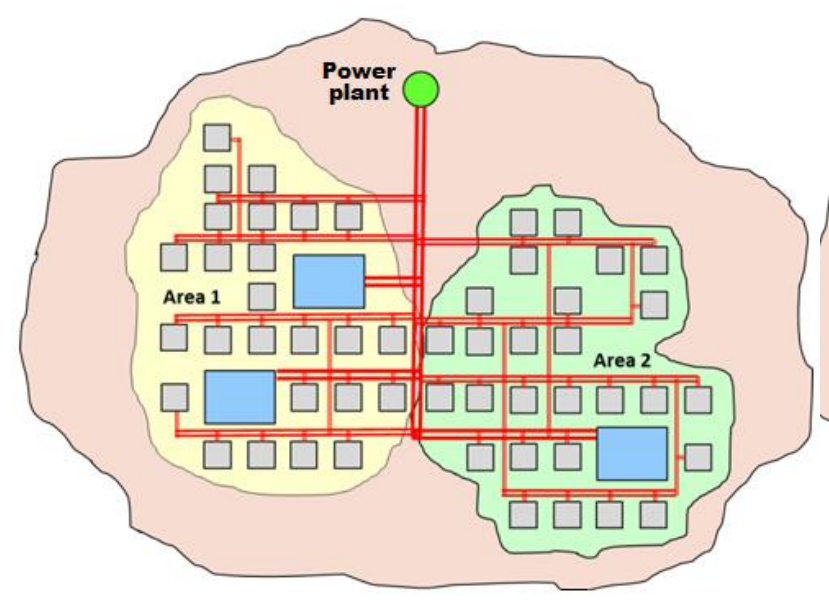

a.

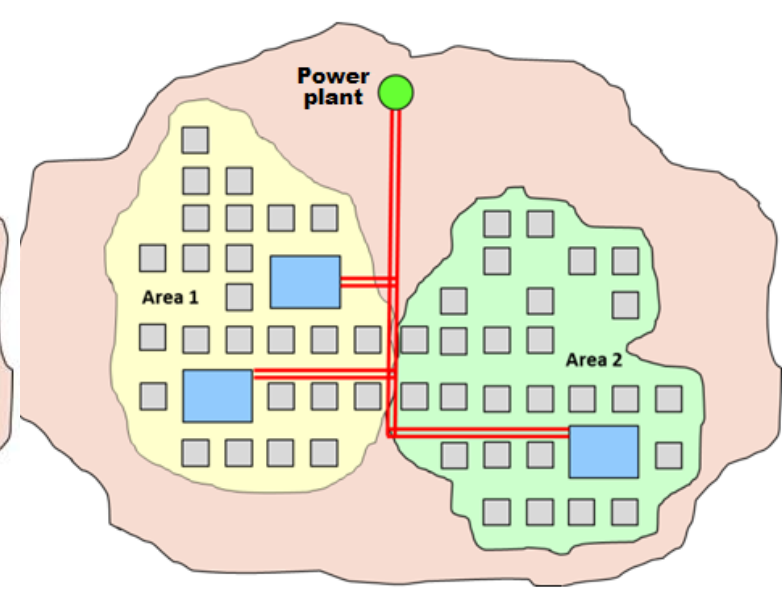

b.

Figure 8. Representation schema of district heating networks characterized by different interconnection levels: a. high interconnection level, b. low interconnection level

b. Energy uses to be supplied and consequent temperature levels of the distributed fluid. Three scenarios could be in principle considered:

- Distribution of low grade heat for space heating and DHW uses and distribution of cold water for space cooling loads;

- Distribution of high grade heat (via superheated water supply) to supply space heating and domestic hot water and to drive on-site (i.e. within the served buildings) thermallyactivated chillers, like single-effect absorption units, to produce cold water for space cooling purposes;

- Distribution of low-grade heat for space heating and domestic hot water uses only. 
The first of these three scenarios seems less attractive, mainly due to the fact that the number of customers that cover their space cooling loads via cold water supply is extremely low in islands, at least in the residential sector, being most of these loads covered by small scale split airconditioners.

c. Coverage of connection cost: only indirect connection between the DH network and the private users will be considered, thus having separate hydraulic circuits and avoiding any risk of damages and leakages. Then, quite high cost of substations can be estimated, since they must include one (or two) plate heat exchanger(s), controls and heat metering devices; according to a recent survey carried out in Italy, costs in the order of 3-6 k€ $€_{2011}$ and 15-40 $€_{2011}$ can be estimated for "small scale"/residential and "medium-large scale"/centralized users, respectively [30]. In the following of this paper, only voluntary connection of private customers will be considered, assuming two distinct scenarios in terms of coverage of connection cost and share of customers voluntarily requiring to be connected to the network:

- Cost of the substations totally covered by the district heating company, that is for simplicity supposed coincident with the company currently supplying electricity, which owns and operates the diesel engines to be converted in CHP operation mode. In this scenario, obviously, the private customer requiring connection to the $\mathrm{DH}$ network would have no initial costs, and the following high shares of customers voluntarily requiring connection are supposed:

- 30\% of residential users as concerns space heating loads (this low percentage is influenced by the high share of residences not interested in hot water supply, being served in winter by small heat pumps);

- $60 \%$ of residential users as concerns domestic hot water loads.

- Cost of the substations totally covered by private customer requiring connection to the DH network. From the customer perspective, the initial investment obviously represents a barrier that contributes to make connection to the DH network unattractive; then, in this scenario lower shares of customers voluntarily requiring connection are supposed, as follows:

- $10 \%$ of residential users as concerns space heating loads;

$-30 \%$ of residential users as concerns domestic hot water loads.

It may be observed that no differences have been supposed for the centralized users, since most of them have usually hydronic systems for space heating and cooling and therefore such customers are supposed to require connection to the DH network regardless of the assumption made for the coverage of connection costs.

For each possible combination of the aforementioned scenarios, the procedure followed to estimate the distribution costs and the most promising network geometry is now described. For the sake of clarity, the analysis will be presented for one of the 6 examined islands, i.e. Lampedusa, which probably represents the most complex but interesting case study. The procedure consists of the following main steps:

1. Definition of a reasonable path for the main line (i.e. line with highest diameters and flow rates) of a DH network connecting the power plant (where heat is made available from engines) with all the identified built areas. All the main lines are consecutively numbered, as shown in Figure 9 for the island of Lampedusa, and their length is calculated; 


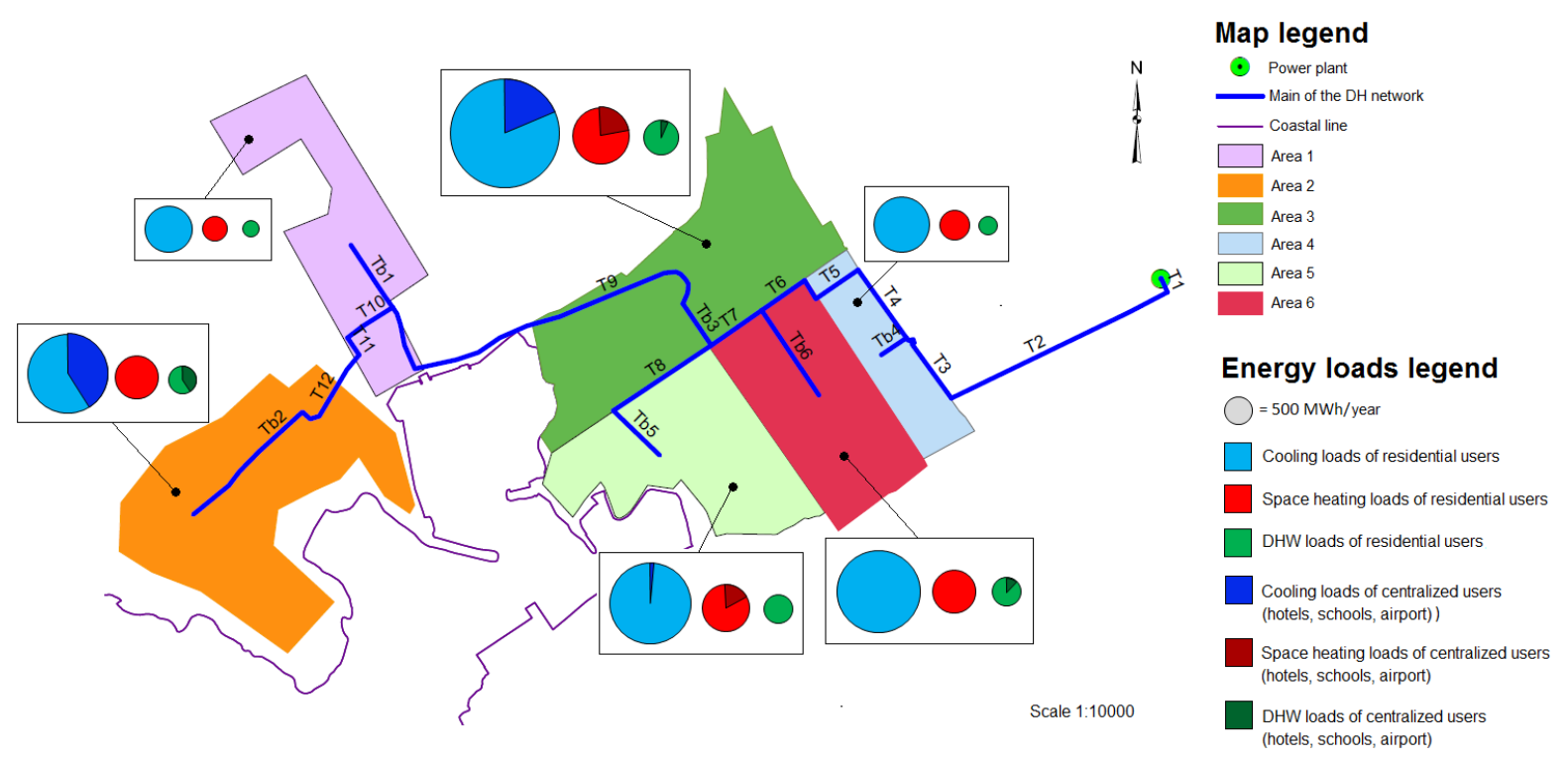

Figure 9. Representation of a reasonable path for the main line of a DH network covering the 6 built areas identified in Lampedusa.

2. An incidence matrix is developed (see table in the upper part of Figure 10) to identify for each served area which main lines contribute to transfer heat toward the area. A generic coefficient $\alpha_{\mathrm{ij}}$ in this matrix is 1 if the area " $\mathrm{j}$ " is supplied by the main line "i", otherwise is 0 . Then, the "length" of each main line (and its cost, in the next steps) is virtually allocated to the areas it serves; if an upstream line of the main serves different downstream areas (as easily identifiable by the incidence matrix), this allocation is made by sharing the line length $l_{i}$ to the served areas proportionally to their total heat loads Q (Eq.5):

$$
l_{i}^{\text {allocatedto Area } j}=\sum_{i \in\{\text { mainlines }\}} \frac{\alpha_{i j} Q_{j}}{\sum_{j \in\{\text { Areas }\}} \alpha_{i j} Q_{j}} \cdot l_{i} \quad[\mathrm{~m}]
$$

This allocation/attribution of the main line (and its associated cost) to each served area is necessary to evaluate at what extent distributing heat toward the area is economically convenient. Then, for each area, a total length of "main + branches" lines is calculated summing up, to the above term, the additional length on intra-area branch lines needed to distribute the hot fluid toward the users (see table in the lower part of Fig. C). Of course, the total length of these branch lines differs for the "high" and the "low" interconnection scenarios presented in Figure 8. The implementation of this step is shown in Figure 10. It is intuitive that the same data presented in this last table could be rearranged oppositely; in fact, for each main line, it could be immediately calculated (considering the supplied areas and their individual heat loads) the amount of heat distributed. Such calculations were also performed (and will be used in the next step), but they are not presented here in details for the sake of brevity. 


\begin{tabular}{|c|c|c|c|c|c|c|c|c|c|c|}
\hline $\begin{array}{l}\text { Branch of } \\
\text { the main }\end{array}$ & $\begin{array}{c}\text { Length } \\
{[\mathrm{m}]}\end{array}$ & Airport & Area 1 & 1 Area 2 & Area 3 & Area 4 & Area 5 & Area 6 & & \\
\hline T1 & 34,5 & 1 & 1 & 1 & 1 & 1 & 1 & 1 & & \\
\hline $\mathrm{T} 2$ & 540,7 & 1 & 1 & 1 & 1 & 1 & 1 & 1 & & \\
\hline T3 & 371,3 & & 1 & 1 & 1 & 1 & 1 & 1 & & \\
\hline T4 & 371,3 & & 1 & 1 & 1 & & 1 & 1 & & \\
\hline T5 & 163,6 & & 1 & 1 & 1 & & 1 & 1 & & \\
\hline T6 & 255,5 & & 1 & 1 & 1 & & 1 & 1 & & \\
\hline $\mathrm{T7}$ & 255,5 & & 1 & 1 & 1 & & 1 & & & \\
\hline T8 & 264,6 & & & & & & 1 & & & \\
\hline T9 & 716,0 & & 1 & 1 & & & & & & \\
\hline $\mathrm{T} 10$ & 122,8 & & & 1 & & & & & & \\
\hline T11 & 46,5 & & & 1 & & & & & & \\
\hline T12 & 209,9 & & & 1 & & & & & & \\
\hline T13 & 521,1 & 1 & & & & & & & & \\
\hline Tb1 & 168,5 & & 1 & & & & & & & \\
\hline $\mathrm{Tb} 2$ & 338,3 & & & 1 & & & & & & \\
\hline Tb3 & 113,1 & & 1 & 1 & 1 & & & & & \\
\hline Tb4 & 67,7 & & & & & 1 & & & & \\
\hline Tb5 & 144,8 & & & & & & 1 & & & \\
\hline \multirow[t]{2}{*}{ Tb6 } & 230,1 & & & & & & & 1 & & \\
\hline & \multicolumn{3}{|c|}{ main, $\Sigma I_{i}{ }_{j}^{\text {allocated to Area }}$} & \multicolumn{3}{|c|}{$\begin{array}{c}\Sigma I_{\text {branches }}{ }^{\text {to centralized }} \\
\text { users } \\
{[\mathrm{m}]}\end{array}$} & \multicolumn{2}{|c|}{$\begin{array}{l}\Sigma I_{\text {branches }}{ }^{\text {to residential }} \\
\text { users } \\
{[\mathrm{m}]}\end{array}$} & $\begin{array}{l}\text { Itotal allocated to Area j, } \\
\text { "low interconnection } \\
\text { level" scenario [m] }\end{array}$ & $\begin{array}{l}\mathrm{I}^{\text {total }} \text { allocated to Area j, } \\
\text { "high interconnection } \\
\text { level" scenario [m] }\end{array}$ \\
\hline Airport & \multicolumn{3}{|c|}{0} & \multicolumn{3}{|c|}{0} & \multicolumn{2}{|r|}{0} & 0 & 0 \\
\hline Area 1 & \multicolumn{3}{|c|}{837} & \multicolumn{3}{|c|}{0} & \multicolumn{2}{|r|}{1048} & 837 & 1885 \\
\hline Area 2 & \multicolumn{3}{|c|}{1216} & \multicolumn{3}{|c|}{968,8} & \multicolumn{2}{|r|}{1999} & 2185 & 4184 \\
\hline Area 3 & \multirow{2}{*}{\multicolumn{3}{|c|}{$\begin{array}{l}479 \\
144\end{array}$}} & \multicolumn{3}{|c|}{103,5} & \multicolumn{2}{|r|}{4616,5} & 583 & 5199 \\
\hline Area 4 & & & & \multirow{2}{*}{\multicolumn{3}{|c|}{$\begin{array}{c}0 \\
245\end{array}$}} & \multirow{2}{*}{\multicolumn{2}{|c|}{$\frac{847}{22156}$}} & 144 & 991 \\
\hline Area 5 & \multicolumn{3}{|c|}{631} & & & & & & 876 & 3091 \\
\hline Area 6 & \multicolumn{3}{|c|}{302} & \multicolumn{3}{|c|}{0} & & 2328 & 302 & 2630 \\
\hline
\end{tabular}

Figure 10. "High" and the "low" interconnection scenarios.

3. Approximate values of distribution cost are calculated, for each line of the main, basing on the Eq. (6) proposed by Persson et al. [17]:

$$
C_{d}=\frac{a \cdot\left(C_{1}+C_{2} \cdot d_{a}\right)}{\left(\frac{Q_{S}}{L}\right)}[€ / \mathrm{GJ}]
$$

where: $a$ is the annuity, $\mathrm{C}_{1}$ is the construction cost constant (in $€ / \mathrm{m}$ ) that depends on the specific diameter of each main line, $C_{2}$ is the construction cost coefficient (in $€ / \mathrm{m}^{2}$ ), $d_{a}$ the average pipe diameter (in $\mathrm{m}$ ) and $\mathrm{L}$ the trench length (considering only the supply pipe). Qs is the heat annually sold (in GJ/year), thus $\mathrm{Q}_{\mathrm{S}} / \mathrm{L}$ representing the so called linear heat density. Appropriate values of the constants $\mathrm{C}_{1}$ and $\mathrm{C}_{2}$, which depend on urbanistic features of the site, were derived from literature [31]. For each scenario, the Cd values were calculated for all the trenches of the DH main. As an example, the results obtained for the island of Lampedusa are shown in Figures 11 and 12. In particular, in Figure 11, the results are shown for the scenario assuming the cost of substations totally covered by private customers. Conversely, in Figure 12 the results are presented for the scenario assuming the cost of substations entirely covered by the company owning and operating the DH network. Furthermore, in both the figures, some reference lines derived by Eq. (6) are shown, referring to small $(30 \mathrm{~mm})$, medium $(80 \mathrm{~mm})$ and large $(150 \mathrm{~mm})$ diameters, which assuming a flow rate consistent with the typical pressure drops usually adopted (in the order of $150 \mathrm{~Pa} / \mathrm{m}$ ) and a temperature difference $\Delta \mathrm{T}=\mathrm{T}_{\text {supply }}-\mathrm{T}_{\text {return }}=25^{\circ} \mathrm{C}$ (both these assumptions will be maintained below in the paper), corresponds to heat distribution rates ranging between $70 \mathrm{~kW}$ and $3 \mathrm{MW}$, as shown in the Figure legend. For each main trench, a 
reasonable diameter coherent with the aforementioned pressure drops was preliminarily calculated, so as to position the corresponding point (identified in the labels) on the graph.

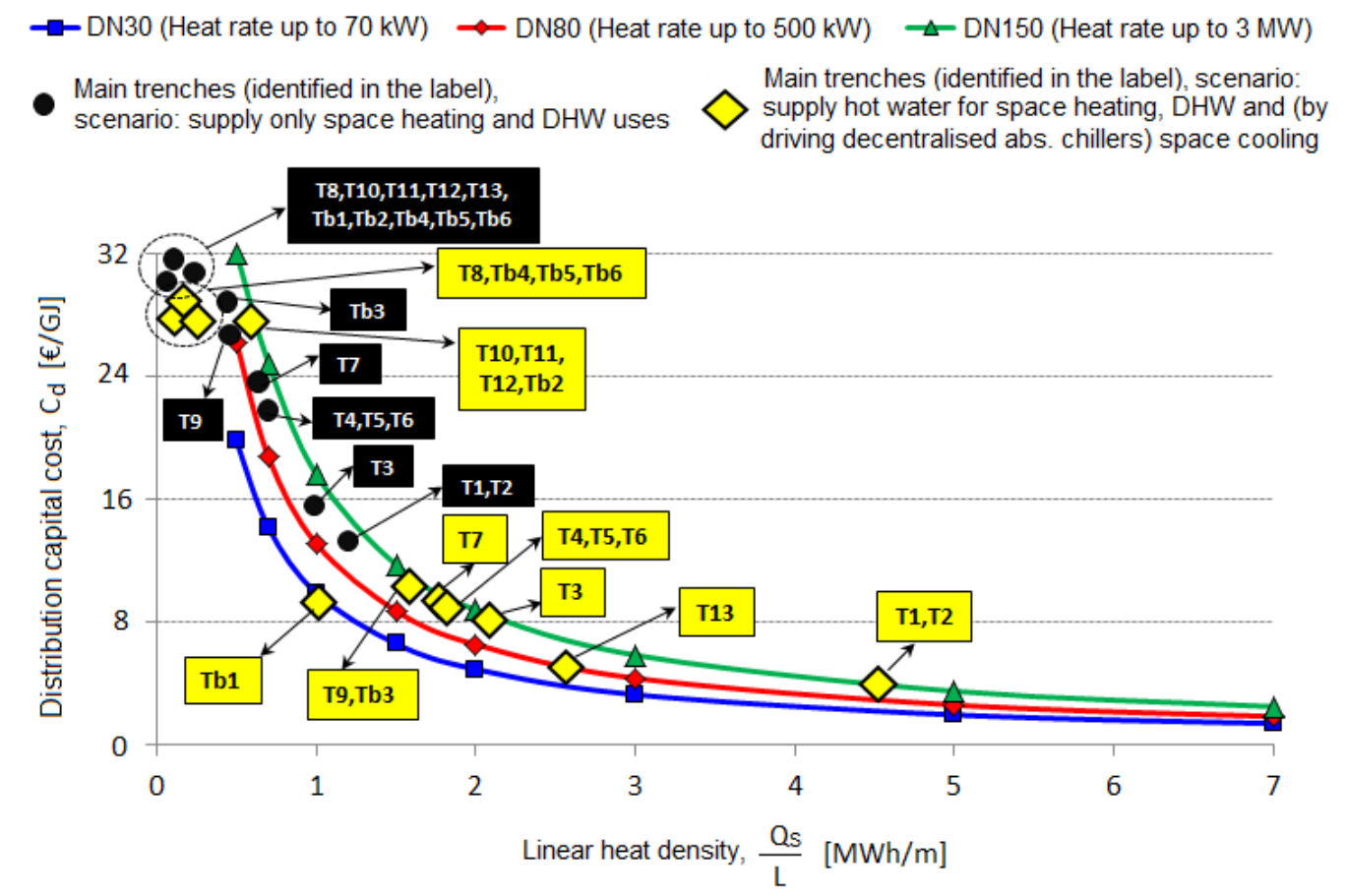

Figure 11. Distribution costs in the scenario of connection costs covered by the private customers

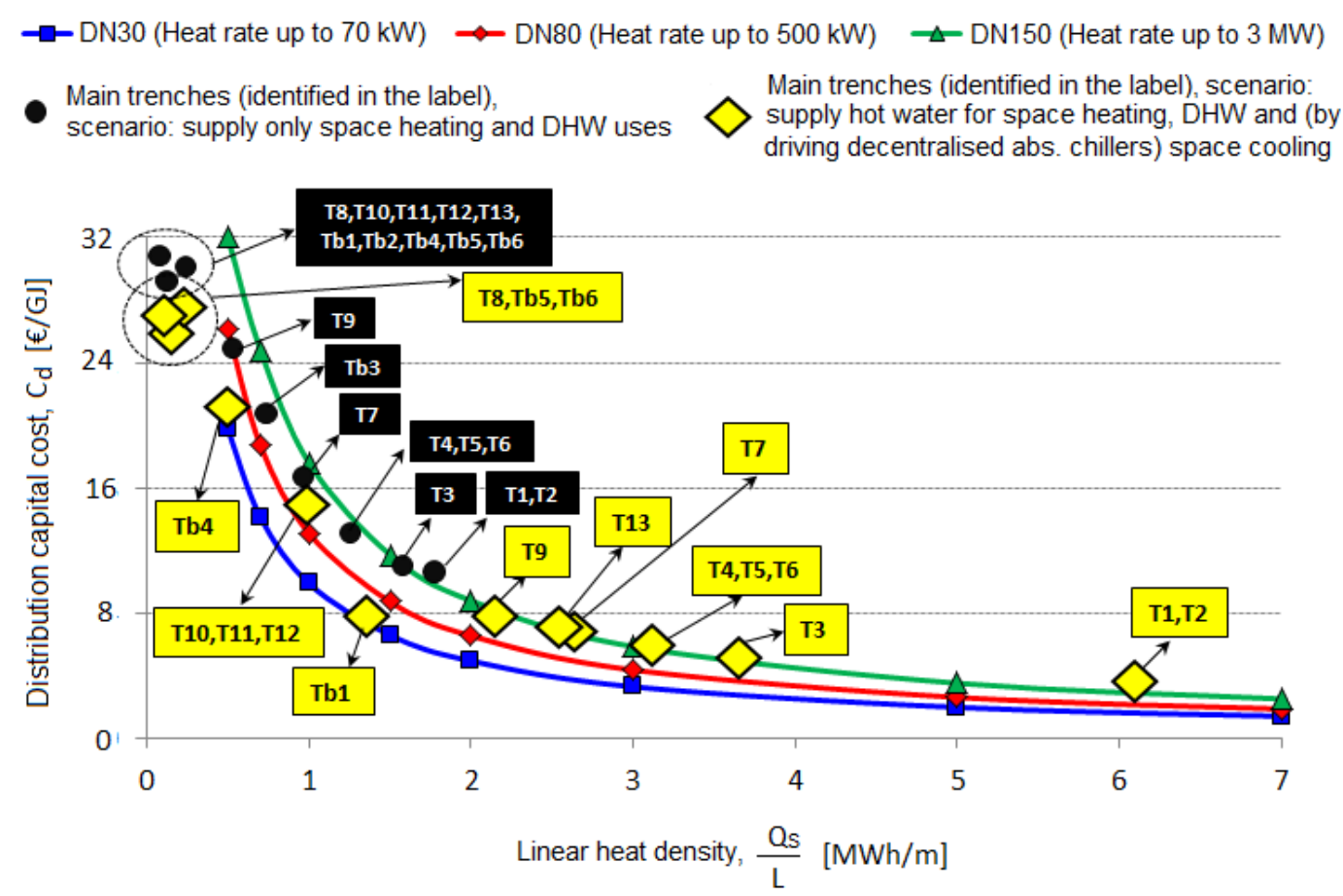

Figure 12. Distribution costs in the scenario of connection costs covered by the company owning and operating the $\mathrm{DH}$ network

Considering that a feasibility condition for a $\mathrm{DH}$ pipe/trench is usually indicated as a minimum 1.5-1.8 MWh/m linear heat density (corresponding to distribution costs not higher than 8-10 $€ /$ GJ, as evident in Figures 11 and 12), we may easily observe that: 
-In the examined island (i.e. Lampedusa), for both the scenarios concerning the coverage of connection costs, the supply of hot water for space heating, DHW and space cooling (by onsite production via thermally-driven chillers) is much more viable than the supply of hot water for space heating and DHW only. In fact, the linear heat density corresponding to the former scenario (indicated by yellow diamond-type markers in Figures 11 and 12) is much higher (and the distribution cost consequently lower) than the heat density corresponding to the latter scenario (indicated by black bullets in Figures 11 and 12). Then for the examined island, due to the prevalence of cooling loads (compared to space heating and DHW ones, see Figure 9), induced in its turn by the high touristic vocation of the islands which makes the number of occupants in the summer period much higher than in winter, only a heat distribution system designed to supply energy to cover all the thermal and cooling requests could be at some extent economically justifiable;

-From a comparison between the distribution of the yellow diamond-type marks in Figure 11 and 12, it is evident that most of the pipes/trenches achieve much higher linear heat densities (and much lower distribution costs) in the scenario with "coverage of distribution costs by the company owning the network" (see Figure 12) compared to the costs in the scenario with "coverage of distribution costs by the private customers" (see Figure 11). Then, the much lower connection rate assumed in this latter scenario would represent a strong barrier to the feasibility of the network, inducing to consider the former scenario as the most attractive;

-A limited number of pipes (T8, T10, T11, T12, Tb4, Tb5 and Tb6) resulted not economically viable. The cause of their high distribution cost is evident in Figure 9: they distribute hot water only toward the Areas 1 and 2, which are characterised by low energy loads and are the farthest from the power plant. Then, limiting the extension of the main of the DH network to the pipes distributing heat toward the Areas 1-4 (the only ones resulted Economically Viable, EV) seems to be the preferable solution. However, in the framework of this particular study, the analysis is carried out by assuming to distribute heat also toward these two small areas (via Non Economically Viable pipes, NEV). In fact, the study is aimed at finding a reasonable compromise between the economic viability of the designed solution and the public interest to increase as much as possible the share of energy loads covered by CHP.

Similar analysis were performed for all the six examined islands, again identifying the most promising scenarios, the economically viable pipes of the main configuration and, eventually, assuming a final design with a slightly larger DH network configuration (i.e. including some Not Economically Viable pipes), in order to maximise the energy loads covered by CHP. The results for the six examined islands are schematically resumed in Table 4.

Table 4. Most promising scenarios identified on the basis of distribution costs diagrams

\begin{tabular}{|c|c|c|c|c|c|c|c|}
\hline \multirow[t]{2}{*}{ Island } & \multicolumn{2}{|c|}{$\begin{array}{l}\text { Most attractive scenario } \\
\text { as concerns the } \\
\text { coverage of connection } \\
\text { costs }\end{array}$} & \multicolumn{2}{|c|}{$\begin{array}{l}\text { Most attractive scenario } \\
\text { as concerns the energy } \\
\text { uses to be supplied }\end{array}$} & \multirow{2}{*}{$\begin{array}{l}\text { Total extension } \\
\text { of the viable } \\
(\text { cost }<10 € / \mathrm{GJ}) \\
\text { main pipes }[\mathrm{m}]\end{array}$} & \multirow{2}{*}{$\begin{array}{l}\text { Total } \\
\text { extension of } \\
\text { the main pipes } \\
\text { assumed to } \\
\text { install }[\mathrm{m}]\end{array}$} & \multirow{2}{*}{$\begin{array}{l}\text { Range of } \\
\text { distribution costs } \\
\text { for the Viable } \\
(\mathrm{EV}) \text { and Not } \\
\text { Viable }(\mathrm{NEV}) \\
\text { main pipes [€/GJ] }\end{array}$} \\
\hline & $\begin{array}{l}\text { Coverage } \\
\text { by private } \\
\text { customers }\end{array}$ & $\begin{array}{l}\text { Coverage } \\
\text { by DH } \\
\text { company }\end{array}$ & $\begin{array}{l}\text { Space } \\
\text { heat. + } \\
\text { DHW }\end{array}$ & $\begin{array}{l}\text { Space heat. } \\
+ \text { DHW + } \\
\text { Space cool. }\end{array}$ & & & \\
\hline Lampedusa & & $x$ & & $x$ & 3398.1 & 4484.6 & $\begin{array}{c}\text { EV: } 3.9-8.1 \\
\text { NEV: } 14.8-27.4\end{array}$ \\
\hline Favignana & & $x$ & $x$ & & 0.0 & 2789.1 & $\begin{array}{c}\text { EV: No viable } \\
\text { pipes } \\
\text { NEV: } 16.4-52.3\end{array}$ \\
\hline
\end{tabular}




\begin{tabular}{|c|c|c|c|c|c|c|c|}
\hline Pantelleria & $x$ & & & $x$ & 2231.8 & 7005.7 & $\begin{array}{c}\text { EV: } 7.2-9.1 \\
\text { NEV: } 27.4-46.9\end{array}$ \\
\hline Ustica & & $x$ & $x$ & & 0.0 & 683.9 & $\begin{array}{c}\text { EV: No viable } \\
\text { pipes } \\
\text { NEV: } 21.7-33.9\end{array}$ \\
\hline Giglio & & $x$ & $x$ & & 0.0 & 895.9 & $\begin{array}{l}\text { EV: No viable } \\
\text { pipes } \\
\text { NEV: } 25.2-37.4\end{array}$ \\
\hline Linosa & & $x$ & $x$ & & 0.0 & 553.0 & $\begin{array}{c}\text { EV: No viable } \\
\text { pipes } \\
\text { NEV: } 28.7-36.1\end{array}$ \\
\hline
\end{tabular}

We may observe that almost in all the examined cases (with the only exception of Pantelleria) having the connection costs covered by the company owning and operating the DH network is preferable, due to the much higher linear heat density achievable. As concerns the energy uses to be supplied, limiting the hot water distribution to cover the space heating and domestic hot water uses is in general preferable; only in two islands (Lampedusa and Pantelleria) the distribution of hot water to feed decentralised thermally driven chillers resulted the most promising option.

\section{(iii) Identification of reasonable supply temperatures and type of pipes to be installed Second level headings}

In the previous subsection a reasonable network configuration and the specific energy uses to be supplied via distributed hot water have been identified. Now, for each of the examined island, design assumptions concerning the hot fluid supply temperature and the type of pipes to be installed are briefly discussed. In particular, two main solutions are identified:

a. For islands where only space heating and Domestic Hot Water uses must be covered, the hot water may be distributed at moderately high temperatures. However, there is no need to consider very low supply temperatures, since the heat losses through the insulated pipes do not represent a major issue, due to $(i)$ the temperate climatic conditions, (ii) the moderate amounts of heat distributed, on annual basis, (iii) the fact that the available waste heat from the engines often exceeds the requests and may be considered as "free". Then, a $\mathrm{T}_{\text {supply }}=85^{\circ} \mathrm{C}$ and a $\mathrm{T}_{\text {return }}=60{ }^{\circ} \mathrm{C}$ were assumed. As concerns the pipes to be installed, the operating conditions allow for installation of cross-linked polyethylene pipes which ensure safe operation at pressures up to 12-14 bars (which have been verified compatible with the expected operating conditions, also keeping into account the altimetric profile of the $\mathrm{DH}$ network derived by an orographic study of the sites);

b. For the two islands where space heating, DHW and space cooling loads must be supplied, the supply temperature must be consequently higher to drive the decentralised absorption chillers. Then, it is assumed to distribute superheated water at $\mathrm{T}_{\text {supply }}=110{ }^{\circ} \mathrm{C}$, with a $\mathrm{T}_{\text {return }}=85^{\circ} \mathrm{C}$. In order to allow for safe operation, pre-insulated steel pipes are assumed to be installed. Of course, when calculating the total cost of the network, costs for special elements such as expansion joints will be included.

\section{(iv) Evaluation of investment costs and possible revenues from selling heat to private/public customers}

The investment cost for the DH company (assumed, as said before, coincident with the company that owns and operates the power plants) was calculated by the following Eq. (7): 


$$
C_{\text {total }}=C_{C H P \text { retr. }}+C_{\text {abs.ch. }}+C_{\text {pipes }}+C_{\text {spec.el. }}+C_{\text {civ. }}+C_{\text {instal. }}+C_{\text {subst. }}
$$

where:

- $\mathrm{C}_{\mathrm{CHP} \text { retr. }}$ indicates the cost for the CHP retrofit of the diesel engines. This retrofit essentially requires installation of shell and tube heat exchangers for high temperature recovery from hot gases (unit cost in the order of $100-120 € / \mathrm{kW}$ ) and plate heat exchangers for low temperature recovery from the jacket cooling water circuit (unit cost in the order of 110-130 kW);

- $\mathrm{C}_{\mathrm{abs} . c h .}$ indicates the cost for the absorption chillers. The inclusion of this cost component in the financial evaluation, which is of course pertinent only in the two cases (Lampedusa and Pantelleria) where space cooling requests are also covered, suggests that the existence of some Energy Performance Contract (like the so-called "shared savings") between the company and the supplied customers is assumed;

- $\mathrm{C}_{\text {pipes }}$ is the cost of the required length of the main and branch pipes. Several catalogues from different manufactures were examined [32,33], to develop useful correlations between the diameter of the pipe and the cost per unit length (Eq. (8) and (9)):

$$
\begin{array}{ll}
c_{\text {pipes }}^{\text {pre-ins. steele }}=0.002 \cdot N D^{2}+0.123 \cdot N D-16.73 & {[€ / \mathrm{m}]} \\
c_{\text {pipes }}^{\text {polyethilexe }}=0.0011 \cdot N D^{2}+0.6128 \cdot N D-16.73 & {[€ / \mathrm{m}]}
\end{array}
$$

Both the above correlations provide a reasonable estimation of the unit cost of pipes over the range of diameters ND (25 mm, $150 \mathrm{~mm})$.

- $\mathrm{C}_{\text {spec.el. }}$ represents the cost for special elements such as junction boxes, TEE junctions and expansion joints;

- $\mathrm{C}_{\text {civ. }}$ represents the cost for civil works;

- $\mathrm{C}_{\text {instal. }}$ represents the installation cost of the DH network;

- $\mathrm{C}_{\text {subst. }}$ represents the total cost of substations (inclusive of heat exchangers, energy metering and control equipment). This cost is excluded from the total cost for the scenario (adopted only in Pantelleria) that assumes connection costs covered by the private customers.

All these costs were estimated on the basis of average cost figures. Details on the value of each specific cost fraction are not provided for sake of brevity; in Table 5 the capital investments calculated for the whole project (including CHP retrofit and installation of DH network and related equipment) are presented.

Table 5. Capital investment for the whole "CHP retrofit + DH network" project in each island

\begin{tabular}{lc}
\hline \multicolumn{1}{c}{ Island } & $\begin{array}{c}\text { Total investment for the } \\
\text { whole project }[\mathrm{M} €]\end{array}$ \\
\hline Lampedusa & 6.628 \\
Favignana & 4.422 \\
Pantelleria & 3.061 \\
Ustica & 1.235 \\
Giglio & 0.961 \\
Linosa & 0.602 \\
\hline
\end{tabular}

As concerns the net annual revenues, they were calculated as difference between the incomes from heat selling activity and the operating costs (which are usually available broken down into a number of different components). Basing on data available in literature, this last term is at-a-flat- 
rate estimated as $1 \%$ of capital costs. As concerns the cost of heat sold to the private customers, the following prices were derived as average figures in Italy: [34]:

a. Heat for domestic hot water: $45 € / \mathrm{MWh}$;

b. Heat for space heating to residential customers: $90 € / \mathrm{MWh}$;

c. Heat for space heating to centralized commercial/public customers: $70 € / \mathrm{MWh}$;

d. Heat for space cooling to centralized customers: $70 € / \mathrm{MWh}$, which leads to calculate (by assuming a $\mathrm{COP}=1.10$ for double-effect chillers supplied at moderately high temperature) an equivalent $77 € / \mathrm{MWh}_{\text {cooling }}$ cost.

In Table 6 the operating results are presented for the six examined islands.

Table 6. Operating results and net annual revenues for the identified "CHP retrofit $+\mathrm{DH}$ network" configurations

\begin{tabular}{|c|c|c|c|c|c|}
\hline Island & Energy use supplied & $\begin{array}{c}\text { Annual energy } \\
\text { supply } \\
\text { [MWh/year] }\end{array}$ & $\begin{array}{c}\text { Income from } \\
\text { energy } \\
\text { supply[k€/year] }\end{array}$ & $\begin{array}{c}\text { Operating } \\
\text { cost } \\
{[\mathrm{k} € / \text { year }]}\end{array}$ & $\begin{array}{c}\text { Net revenue } \\
\text { [k€/year] }\end{array}$ \\
\hline \multirow{5}{*}{ Lampedusa } & Space heat. (Resid.) & 1851.6 & 166.6 & \multirow{5}{*}{12.5} & \multirow{5}{*}{569.3} \\
\hline & Space heat. (Central.) & 1159.3 & 81.2 & & \\
\hline & DHW & 1495.4 & 67.3 & & \\
\hline & Space cool. (Central.) & 3462.6 & 266.7 & & \\
\hline & Total & & 581.8 & & \\
\hline \multirow{4}{*}{ Favignana } & Space heat. (Resid.) & 1378.0 & 124.0 & \multirow{4}{*}{8.3} & \multirow{4}{*}{201.3} \\
\hline & Space heat. (Central.) & 391.9 & 27.4 & & \\
\hline & DHW & 1293.4 & 58.2 & & \\
\hline & Total & & 209.6 & & \\
\hline \multirow{5}{*}{ Pantelleria } & Space heat. (Resid.) & 441.0 & 39.7 & \multirow{5}{*}{5.7} & \multirow{5}{*}{205.4} \\
\hline & Space heat. (Central.) & 1207.8 & 84.5 & & \\
\hline & DHW & 547.8 & 24.6 & & \\
\hline & Space cool. (Central.) & 1131.9 & 87.2 & & \\
\hline & Total & & 236.0 & & \\
\hline \multirow{4}{*}{ Ustica } & Space heat. (Resid.) & 637.5 & 57.4 & \multirow{4}{*}{2.3} & \multirow{4}{*}{79.6} \\
\hline & Space heat. (Central.) & 173.4 & 12.1 & & \\
\hline & DHW & 275.9 & 12.4 & & \\
\hline & Total & & 81.9 & & \\
\hline \multirow{4}{*}{ Giglio } & Space heat. (Resid.) & 408.5 & 36.8 & \multirow{4}{*}{1.8} & \multirow{4}{*}{59.4} \\
\hline & Space heat. (Central.) & 239.4 & 16.8 & & \\
\hline & DHW & 168.6 & 7.6 & & \\
\hline & Total & & 61.2 & & \\
\hline \multirow{4}{*}{ Linosa } & Space heat. (Resid.) & 147.7 & 13.3 & \multirow{4}{*}{1.1} & \multirow{4}{*}{25.4} \\
\hline & Space heat. (Central.) & 86.6 & 6.1 & & \\
\hline & DHW & 158.5 & 7.1 & & \\
\hline & Total & & 26.5 & & \\
\hline
\end{tabular}




\section{SYNTHETIC ECONOMIC INDICATORS}

In order to perform a more intuitive viability analysis for the "CHP retrofit $+\mathrm{DH}$ network installation" scenarios identified as most promising solutions, for each island the following synthetic economic indicators were derived:

- The Net Present Value (NPV), defined as shown in Eq. (10):

$$
N P V=-C_{\text {total }}+\sum_{j=1}^{n_{\text {life }}} \frac{\text { Net Revenue }_{j}}{\left(1+i_{\text {def }}\right)^{j}}
$$

In. Eq. 10 the term " $i_{d e f}$ " (here assumed equal to 5\%) represents the "real" discount rate (which neutralizes the effects of inflation on the nominal value of future net revenues) needed to adopt the "constant currency" approach, while the Net Revenue represents the annual income from energy selling.

- Discounted Payback Time (DPT), evaluated as following Eq. (11):

$$
D P T=\min \kappa \mid\left[-C_{t_{\text {total }}}+\sum_{j=1}^{\kappa} \frac{\text { Net Revenue }_{j}}{\left(1+i_{\text {def }}\right)^{j}} \geq 0\right]
$$

- Profitability Index, a dimensionless indicator calculated as shown in following Eq. (12):

$$
P I=\frac{N P V}{C_{\text {total }}}
$$

Due to the low linear heat density and the consequently high investment costs presented in Table 5 , it can be easily predicted that the designed configurations will result scarcely or moderately attractive from an economic viewpoint. However, the results are made even worse by the decision to extend the DH network also with some "Not Economically Viable" main and branch pipes, in order to fulfil the public interests to have $(i)$ a higher share of the heat/cooling loads covered by "free" energy recovered from diesel engines' operation and (ii) the possibility to reduce the production cost of electricity in islands, thus being possible to reduce the incentives currently assigned with the subsidized feed-in tariff "UC4" (see Section 2). As a consequence, it is worthwhile deriving the above synthetic indicators for two reference conditions:

1. Absence of incentives or support mechanisms. The viability of the examined configurations are assessed basing on the results (in terms of capital investment and net annual revenues) obtained in the previous section;

2. Presence of currently available incentives and further "ad hoc" support mechanisms. In particular, two simultaneous financial supports will be considered:

- Coverage of $30 \%$ of the total capital investment for the projects (i.e. $\mathrm{C}_{\text {total }}$ ) by public subsidies

- Additional annual revenues deriving from the sell of the specific amount of White Certificates that each project is expected to attain, based on the energy savings it achieves. The number of White Certificates [35] assigned may be calculated by Eq. (13):

$$
N_{W C}=0.086 \cdot K \cdot\left(\frac{E_{C H P}}{\eta_{e}^{r e f}}+\frac{H_{C H P}}{\eta_{t}^{r e f}}-F_{C H P}\right)
$$

where: $\mathrm{K}$ is fixed equal to 1.3 for $\mathrm{CHP}$ plants with capacity between $1 \mathrm{MW}_{\mathrm{e}}$ and 10 $\mathrm{MW}_{\mathrm{e}}, \eta_{\mathrm{e}}^{\mathrm{ref}}$ and $\eta_{\mathrm{t}}^{\text {ref }}$ respectively represents the reference efficiency for separate power 
and heat production (fixed equal to 0.46 and 0.90 by the referenced National legislation), and $E_{C H P}, H_{C H P}$ and $F_{C H P}$ represent the Electricity and useful Heat produced and the Fuel consumed in "efficient CHP mode", according to the provisions of Directive 2004/8/EC [36]. It is assumed that the whole amount of heat cogenerated is produced in "efficient CHP" mode; this condition is realistic, due to the low reference efficiency recommended for diesel-fuelled units.

Table 7. Synthetic indicators of economic viability for the scenarios with and without incentives

\begin{tabular}{lcccccc}
\hline \multirow{2}{*}{ Island } & \multicolumn{2}{c}{ NPV [k€] } & \multicolumn{2}{c}{ DPT [years] } & \multicolumn{2}{c}{ PI [dimensionless] } \\
& $\begin{array}{c}\text { Without } \\
\text { incentives }\end{array}$ & $\begin{array}{c}\text { With } \\
\text { incentives }\end{array}$ & $\begin{array}{c}\text { Without } \\
\text { incentives }\end{array}$ & $\begin{array}{c}\text { With } \\
\text { incentives }\end{array}$ & $\begin{array}{c}\text { Without } \\
\text { incentives }\end{array}$ & $\begin{array}{c}\text { With } \\
\text { incentives }\end{array}$ \\
\hline Lampedusa & 2686.9 & 5458.7 & 17.4 & 9.8 & 0.405 & 1.199 \\
Favignana & -1199 & 651.8 & Not available & 21.1 & -0.271 & 0.231 \\
Pantelleria & 687.7 & 1863.8 & 20.2 & 11.1 & 0.225 & 0.852 \\
Ustica & 23.9 & 535.5 & $>30$ & 13.7 & 0.02 & 0.659 \\
Giglio & -21.7 & 396.7 & Not available & 13.8 & -0.023 & 0.651 \\
Linosa & -194.8 & 52.1 & Not available & 24.2 & -0.324 & 0.135 \\
\hline
\end{tabular}

The results are shown in Tab. 7 and their comparison with the detailed data provided for each island in the previous sections allow us to draw some interesting considerations:

1. In case of absence of any support mechanism, in all the examined islands the investment for the "CHP retrofit + DH network installation" is not economically viable. This is an obvious consequence of the low heat density, associated in its turn with the limited demographic density and the prevalence, in the residential sector, of small buildings where space heating and cooling needs are prevalently covered by small split systems;

2. If sufficient incentives are provided, justified by the aforementioned public interests in increasing the average energy conversion efficiency of the existing power units, positive NPVs over the expected plant life cycle span may be achieved. Actually, even in this more favourable scenario the attractiveness of investment remains low, due to the Payback Time often above 10 years and the Profitability Index assuming values below 1 (this value is usually assumed as a minimum threshold for economic viability);

3. The influence of geographical/climatic and demographic variables on the feasibility of the examined solutions is easy-to-examine. Differently than in the analysis of urban DH projects, the climatic conditions (represented by the number of Heating Degree days presented in Table 1) do not seem to play a primary role; despite its largely highest HDD, the "Isola del Giglio" resulted scarcely promising as concerns the feasibility of "CHP retrofit + DH network installation". Conversely, the number of residential/permanent inhabitants seems to favour the attractiveness of this technical solution: the two most populated islands (see Figure 1), Lampedusa and Pantelleria, achieved the highest Profitability Index and the lowest DPT (which resulted below 12 years for the scenario "with incentives"). Ultimately, the relative position between the power plant and the most densely populated area resulted to be another key factor. The island of Favignana, for instance, in spite of its high number of permanent inhabitants, resulted to be $2^{\text {nd }}$ least attractive among the examined islands (see Table 7), being the unique having the power plant being located at high distance from the most densely populated area, as evident in Figure 2. 


\section{CONCLUSION}

In this paper an analysis was carried out for a number of small Italian islands, aimed at assessing the viability of heat recovery from the existing diesel-engine based power plants (currently operated, very inefficiently, in power-production-only mode) and the possible distribution of heat to supply energy loads of both residential and centralized/punctual users. The six examined islands differ by the number of inhabitants, the climatic conditions, the incidence of touristic fluxes on the energy loads and several other factors. Detailed simulations were made, based on a number of scenarios as concerns the energy loads to be covered via the distributed hot/warm or cold fluids and the contribution to the coverage of connection costs; optimal paths for the main and branch lines were determined, based on the linear heat density in the most densely populated areas. Once conducted accurate cost analyses, synthetic economic indicators were derived to assess the viability of the "CHP retrofit + DH network installation" plans. As expected, even for the most promising scenario for each examined island, the proposed solution was far from economic viability, especially due to the extremely low heat density which is, in its turn, induced by the prevalence of "nonhydronic" space heating and cooling systems in residential buildings. In case of inclusion, in the economic analysis, of possible incomes from support mechanisms such as White Certificates for cogeneration and eventual grants covering a fraction of the DH network purchase and installation cost, moderate feasibility could be achieved in some cases, although the investment remained scarcely attractive as proven by the long payback periods. A high number of permanent inhabitants resulted to be the factor most favouring the viability of the examined schemes, while the climatic conditions of the site appeared to play only a secondary role. Of course, the results are highly sensitive to specific conditions such as, for instance, the distance between the power plant and the most densely populated areas.

\section{CONTRIBUTION OF AUTHORS}

As concerns the contribution to the work, Dr. Leone Dr. Galatioto Dr. Ciulla have performed the territorial analysis of the islands, collected and organised information related to the end uses per categories and built the dynamic models for the energy loads evaluation. Prof. Piacentino defined the scenarios and designed the CHP retrofit and DH network solutions, sizing the plant components, identifying the network geometries and sizing the lines, and performing all the energo-economic analyses. Dr. Di Pietra managed the information flow between the research team and electric utilities and public authorities. Prof. Beccali coordinated the whole project and supervised all the phases of the work.

\section{REFERENCES}

1. N. Duić, G. Krajačić, M. da Graça Carvalho. RenewIslands methodology for sustainable energy and resource planning for islands. Renewable and Sustainable Energy Reviews, 2008, Vol. 12, p. 1032-1062

2. R. Segurado, M. Costa, N. Duić, M.G. Carvalho. Integrated analysis of energy and water supply in islands. Case study of S. Vicente, Cape Verde. Energy, 2015, Vol. 92, p. 639-648.

3. P. Moss, J. Manrique de Lara y Gil. Twenty-five years of desalination in the Canary Islands: an historical review of the application of reverse osmosis using case studies and operational experience. Desalination, 1999, Vol. 125, p. 17-23.

4. Y. Kuang, Y. Zhang, B. Zhou, C. Li, Y. Cao, L. Li, L. Zeng. A review of renewable energy utilization in islands. Renewable and Sustainable Energy Reviews, 2016, Vol. 59, p. 504-513. 
5. G. Notton. Importance of islands in renewable energy production and storage: The situation of the French islands. Renewable and Sustainable Energy Reviews, 2015, Vol. 47, p. 260269.

6. T.B. Tsuchida, Chapter 24 - Renewables Integration on Islands, in "Renewable Energy Integration - Practical Management of Variability, Uncertainty and Flexibility in Power Grids", 2014, Editor L.E. Jones, Academic Press, p. 295-305.

7. A. Heydari, A. Askarzadeh. Optimization of a biomass-based photovoltaic power plant for an off-grid application subject to loss of power supply probability concept. Applied Energy, 2016, Vol. 165, p. 601-611.

8. T. Sakaguchi, T. Tabata. $100 \%$ electric power potential of PV, wind power, and biomass energy in Awaji island Japan. Renewable and Sustainable Energy Reviews, 2015, Vol. 51, p. 1156-1165.

9. Union of the Electricity Industry-EURELECTRIC. Report: EU islands: Towards a sustainable energy future. Brussels (Belgium), 2012. Available at url: http://www.eurelectric.org/media/38999/eu_islands_-

_towards_a_sustainable_energy_future_-_eurelectric_report_final-2012-190-0001-01-e.pdf , Accessed on February 23rd, 2016.

10.D. Fielde, J.K. Jacques. Distributed cogeneration can have a very meaningful strategic energy conservation outcome for islands. International Journal of Energy Research, 1997, Vol. 21, p. 885-898.

11.CODE2 Project - Cogeneration Observatory and Dissemination Europe. Final Report Section D5.1: Final Cogeneration Roadmap non pilot Member State: Malta. 2014. Available at url: http://www.code2-project.eu/wp-content/uploads/CODE2-D5.1-Roadmap-MaltaDec14.pdf, Accessed on February 23rd, 2016.

12.D. Čulig-Tokić, G. Krajačić, B. Doračić, B. Vad Mathiesen, R. Krklec, J. Møller Larsen. Comparative analysis of the district heating systems of two towns in Croatia and Denmark. Energy, 2015, Vol. 92, p. 435-443

13.H. Lund, S. Werner, R. Wiltshire, S. Svendsen, J.E. Thorsen, F. Hvelplund, B. Vad Mathiesen. 4th Generation District Heating (4GDH): Integrating smart thermal grids into future sustainable energy systems. Energy, 2014, Vol. 68, p. 1-11.

14.T. Ommen, W. Brix Markussen, B. Elmegaard. Lowering district heating temperatures Impact to system performance in current and future Danish energy scenarios. Energy, 2016, Vol. 94, p. 273-291.

15.P.A. Østergaard, H. Lund. A renewable energy system in Frederikshavn using lowtemperature geothermal energy for district heating. Applied Energy, 2011, Vol. 88, p. 479487.

16.U. Persson, B. Möller, S. Werne. Heat Roadmap Europe: Identifying strategic heat synergy regions. Energy Policy, 2014, Vol. 74, p. 663-681.

17.U. Persson, S. Werner. Heat distribution and the future competitiveness of district heating. Applied Energy, 2011, Vol. 88, p. 568-576.

18.Available at url: http://www.autorita.energia.it/it/elettricita/schede/auc_05.htm, Accessed on Apr 31st, 2016.

19.ISTAT. Population Housing Census. in http://daticensimentopopolazione.istat.it/Index.aspx?lang=it Accessed on Apr 27th, 2016.

20.Daluiso E., Il turismo in Puglia nel 2012-2013 e le prospettive di crescita al 2020, Euroidees, Bruxelles, gennaio 2014.

21.Available at url: http://apps1.eere.energy.gov/buildings/energyplus/, Accessed on April 27th, 2016.

22.Comitato Termotecnico Italiano - CTI, Prestazioni energetiche degli edifici: climatizzazione invernale e preparazione acqua calda sanitaria per usi igienico-sanitari, Roma, 2003. 
23.Regione Siciliana-Assessorato al turismo, comunicazione e trasporti, Alberghi di Sicilia. Vademecum della ricettività alberghiera ed extra-alberghiera in Sicilia, 2005-2006.

24.Beccali M., La Gennusa M., Lo Coco L., Rizzo G., An empirical approach for ranking environmental and energy saving measures in the hotel sector, Renewable Energy 34, 82-90, 2009

25.UNI TS 11300-2:2014. Energy performance of buildings - Part 2: Evaluation of primary energy need and of system efficiencies for space heating, domestic hot water production, ventilation and lighting for non-residential buildings.

26.Available at url: http://www.upi-poienergia.eu/, cit. 28/06/2015, Accessed on April 27th, 2016.

27.A. Stoppato, M. Mariano, P. Fornea, M. Marani, Energetic saving in Italian reclusion institutes: experimentation in the town of Padova, 22nd International Conference on Efficiency, Cost, Optimization Simulation and Environmental Impact of Energy Systems, 31agosto -3settembre 2009, Paraná-Brazil.

28.Available at url: https://poin.enac.gov.it/web/sicilia/aeroportolampedusa. Accessed on April 27th, 2016.

29. Available at url: https://poin.enac.gov.it/web/sicilia/aeroporto-pantelleria. Accessed on April 27 th, 2016.

30.Autorità Garante per la Concorrenza del Mercato (Italian Competition Authority). Indagine Conoscitiva sul Settore del Teleriscaldamento (Survey on the District Heating Sector) - IC46 (in Italian). 2011. at Available at url: http://www.agcm.it/indagini-conoscitivedb/download/C12564CE0049D161/763C50A4A6F34653C1257987004D3AA0.html?a=IC46 Chiusura.pdf. Accessed on April 13rd, 2016.

31. U. Persson. Realise the Potential! Cost effective and energy efficient District Heating in European Urban Areas. Graduation Thesis, Dpt. of Energy and Environment, Chalmers University of Technology, Gothenburg, 2011.

32. Commercial catalogue of Bruggpipesystems, related to the set of pipes listed in the product catalogue available at url: http://www.pipesystems.com/en/Catalogue. Accessed on April 26th, 2016.

33. Commercial catalogue of Permapipe, related to the set of pipes listed in the product catalogue available at url: http://www.permapipe.com/productcatalog, Accessed on April 26th, 2016.

34.Taufer GmbH_srl. Connection and heat costs for private customers (in Italian), available at url: http://www.taufer.bz.it/it/fernwaerme/tarifblatt/tarifblatt.php, Accessed on April 26th, 2016.

35.Decree of Italian Ministry of Economic Development of September 5th, 2011. "Support mechanisms for high efficiency cogeneration" (in Italian). GURI, n. 218 of September 19th, 2011.

36.Directive 2004/8/EC of the European Parliament and of the Council. Official Journal of the European Union L 52 (50-60); 2004 (21.02.04). 